\title{
The Romance Inter-Views: Syntax
}

\section{Grant Armstrong}

University of Wisconsin - Madison

\section{Karlos Arregi}

University of Chicago

\section{Karen De Clercq}

CNRS Laboratoire de Linguistique formelle, Université de Paris

\section{Caterina Donati}

CNRS Laboratoire de Linguistique formelle, Université de Paris

\section{Antonio Fábregas}

UIT, The Arctic University of Norway

\section{Luigi Rizzi}

Collège de France

\section{Andrés Saab}

CONICET Buenos Aires and University of Buenos Aires

Norma Schifano

University of Birmingham

\section{The Romance Inter-Views}

The Romance Inter-Views are short, multiple Q\&A pairs that address key issues, definitions and ideas regarding Romance linguistics. Prominent exponents of different approaches to the study of Romance linguistics are asked to answer some general questions from their viewpoint. The answers are then assembled so that readers can get a comparative picture of what's going on in the field. 
For the first Inter-Views we selected (morpho-)syntactic research, and asked 8 syntacticians, representing four approaches to the study of Romance linguistics, to answer our questions. The approaches we selected are Cartography, Distributed Morphology, Minimalism, and Nanosyntax. The scholars we interviewed are listed hereafter.

For Cartography:

Luigi Rizzi, professor of Linguistics at the Collège de France;

Norma Schifano, lecturer in Modern Languages at the University of Birmingham.

For Distributed Morphology:

Karlos Arregi, associate professor in Linguistics at the University of Chicago;

Andrés Saab, associate researcher at CONICET, Buenos Aires and associate professor in Linguistics at the University of Buenos Aires.

For Minimalism:

Grant Armstrong, associate professor of Spanish Linguistics at the University of Wisconsin-Madison;

Caterina Donati, professor of Linguistics at the University Paris Diderot-Paris 7

For Nanosyntax:

Karen De Clercq, CNRS Researcher at the Laboratoire de Linguistique formelle (Université de Paris).

Antonio Fábregas, professor of Linguistics at UIT, The Arctic University of Norway

Keywords: syntax; Romance linguistics; Cartography, Distributed Morphology; Minimalism; Nanosyntax.

\section{What are the main research questions that your research framework deals with?}

\section{Cartography}

Rizzi: As I understand it, cartography is not a framework, but a line of inquiry, a research topic with a broad descriptive dimension, consistent with frameworks such as different versions of minimalism and of principles and parameters. Cartography focuses on the fine details of the different zones of syntactic structures in a comparative perspective.

Schifano: One of the main goals of cartography is to map the fine-grained internal make-up of the CP, IP, NP etc domains. By comparing a wide array of empirical evidence and with special attention paid to microvariation and subtle cross-linguistic differences, it aims at drawing hierarchies as precise as possible of the functional projections which make up such fields.

\section{Distributed Morphology}

Arregi: The defining characteristic of Distributed Morphology (DM) as a framework is that there is no single module of grammar (e.g. the Lexicon) that accounts for all the structural and formal properties of words. Like phrases and 
sentences, words are built in the syntax, and postsyntactic (PF) rules and principles map these syntactically-built structures to form. As such, a central question that guides all work in DM is: For any so-called morphological construction (e.g. a word, or a paradigm), what is the right division of labor in accounting for all of its properties?

Saab: Distributed Morphology aims to provide an answer to the following questions: (i) assuming the general model of grammar provided by Principles \& Parameters, how should we design the syntax-PF interface?, (ii) what is a "lexical item" / "word", and (iii) to what extent does syntax contribute to derive such notion?

\section{Minimalism}

Armstrong: Minimalism is a generative framework that assumes, by hypothesis, the existence of a universal grammar (UG). Research within the framework seeks to model UG in terms of a reduced set of base components (features, lexical items), computational operations, structural and interface constraints. This model intends to accurately describe acceptable and unacceptable structures in any individual's grammar and explain why we observe the types of linguistic diversity that we do.

Donati: What are the tenets of natural language that cannot be reduced to interface requirements or general computational principles? In particular, what properties do we need to ascribe to syntactic objects? Are they always, optionally, or never labeled? Are they always associated with some agree relation or can they be built freely? What is the status of dislocations with respect to structure building operations? What are the locality constraints affecting structures and where do they come from?

\section{Nanosyntax}

De Clercq: How can fine-grained empirical work, i.e. the study of syncretisms and morphological and semantic containment, help us uncover the primitive features of Language and their hierarchical structure, the so called Functional Sequence? How can this fine-grained empirical approach uncover regularities in apparent morphological irregularity, and how can insight in lexical structure help to capture parametric variation?

Fábregas: What Nanosyntax tries to explain is how primitive units -individual features- are packaged together into constituents that correspond to single exponents. This involves identifying the universal structure of languages through the syntactic distribution and role of each exponents in each language and each variety, assuming only syntax, semantics and phonology exist. 


\section{What is the main contribution that your research framework has given to Romance linguistics?}

\section{Cartography}

Rizzi: Detailed tree representations of the structure of CP, IP, DP, etc. in different Romance languages, with particular reference to the sequences of functional elements associated to each zone of the tree. New emphasis on the structural peripheries and their systems of morphological and prosodic markers, and on interface properties with information structure and discourse organization.

Schifano: The Romance languages are well renowned for their spectacular degree of internal microvariation. In that respect, one of the greatest contributions of cartography is to have provided scholars with a frame to predict, investigate and systematize such microvariation in a way that can be fruitfully exploited by other frameworks too.

\section{Distributed Morphology}

Arregi: I would say research into pronominal clitics. Although Romance clitics played an important role in the development of syntactic Principles-andParameters-style theories, the advent of DM in the early 90s brought renewed interest in phenomena involving clitics. For instance, current research into PersonCase Constraint effects, Spanish spurious se, and similar phenomena in other languages owes a lot to observations and analyses that were first made in early DM research.

Saab: First, DM contributed to a better understanding of patterns of syncretism in, for instance, the pronominal clitic systems across Romance. Second, many facts regarding clitic ordering in Romance have received a good account under the assumption that there is more than simple (syntactic or phonological) head movement involved in them.

\section{Minimalism}

Armstrong: It has established a theoretical basis upon which to create and test hypotheses about morphosyntactic variation at the macro and micro levels. While it is certainly the case that some types of variation can be motivated in functional terms, others are quite abstract. Minimalism and its predecessor (the Principles \& Parameters framework) have provided us with an understanding of the innerworkings of these more abstract points of variation among Romance languages and dialects.

Donati: Mimimalism has contributed to understanding micro and macro variation in Romance concerning word order, agreement patterns, subject omission, and subordination types.

\section{Nanosyntax}

De Clercq: M. Starke's keynote talk "Universal Morphology" at NELS 2020 is probably the biggest contribution to Romance linguistics up until now. In his talk 
he uncovers a regular system in 200 French irregular verbs. As such, he shows that language - even at the most idiosyncratic level of morphology- is actually principled and regular, just like syntax.

Fábregas: I would say that nanosyntax provides a framework to analyse variation where all differences among languages derive from the internal constituency of individual exponents, without having to posit parameters or significant sources of variation at other levels. I believe that detailed, fine-grained and very explicit descriptions are still needed in Romance languages, going beyond the mere collection of phenomena or (conversely) declaring very general principles where inconvenient facts are dismissed as quirks.

\section{How do you think your approach differs from others and why is it better?}

\section{Cartography}

Rizzi: Cartography differs from other lines of research in that it focuses primarily on structural configurations and their complexity. From that vantage point, it raises and addresses theoretical questions about the nature of generating mechanisms and computational principles, and explores their explanatory capacity to capture the complexity of structures.

Schifano: More than an approach, cartography has been conceived as a heuristic tool which can be employed by scholars of any theoretical persuasion to formulate research questions and to make predictions to be tested against data (e.g. if the IP can be decomposed into many FPs and the verb moves across the IP, are there any intermediate landing sites?). As such, it is neither better nor worse, but rather complementary to many other approaches, including minimalism.

\section{Distributed Morphology}

Arregi: DM places a lot of emphasis on the distribution of explanatory labor among different parts of grammar and their interaction, in contrast with other more monolithic theories in which, for instance, everything is syntax. As a result, DM research often gives less weight to Occam's Razor-based arguments, and focuses more on trying to figure out how best to explain particular phenomena as emerging from the interaction of independent parts of the grammar.

Saab: Compared to other approaches (e.g., lexicalist ones), DM denies the existence of a lexical component. According to DM, words are the result of welldefined morpho-syntactic principles. This results in an explicit theory of morphosyntax complying with the minimalist desideratum of reducing certain aspects of the language faculty to interface properties.

\section{Minimalism}

Armstrong: Minimalism studies the innate, internal mechanisms at work in the grammars of individual speakers, which by hypothesis are constrained by the principles of a domain-specific UG. In this sense, it differs from frameworks that study patterns of language use and from frameworks that hypothesize the 
existence of internal mechanisms at work in grammar, but do not assign to those any kind of domain specificity (e.g. they may be statistical). I hesitate to claim that any particular framework is better than another. Different frameworks often highlight distinct kinds of linguistic phenomena as primary support, and I like to keep an open mind regarding the merits of different frameworks as it helps advance the field.

Donati: Minimalism sees empirical research and descriptive work as never dissociated from fundamental questions concerning the nature of language, its learnability and evolvability. It is extremely restrictive in the devices it makes available for language description and as such imposes a great depth of analysis at each step.

\section{Nanosyntax}

De Clercq: Unlike other frameworks, the empirical scope of Nanosyntax does not stop at the level of the morpheme, but digs beyond that level, to the nanolevel, uncovering the internal structure of morphemes. Consequently, cross-linguistic variation can be captured as a consequence of differences in the size of lexical structures.

Fábregas: In what I would call a Kaynean tradition, the method used in nanosyntax favours that one starts from a very detailed empirical description of the phenomena, going down to the smallest units, and -because claiming 'Morphology did it' is not an option- forcing oneself to see things under a completely new light. I believe that we need a strongly empirical approach as a base to establish any significant hypothesis about the structure of language, and I feel that not every theory acknowledges the role that fine-grained generalisations should have in shaping any theory.

\section{Is your approach being used for experimental research?}

\section{Cartography}

Rizzi: Yes, cartography is being used as the theoretical underpinning for experimental work in first language acquisition, and for language-related developmental pathologies (autism). There is a clear potential also for experimental work in second language acquisition, aphasiology, and experimental research in computational linguistics.

Schifano: Because of its strong empirical basis, cartography is particularly suited for experimental research, with again special attention paid to patterns of microvariation, witness for example syntactic experiments on the distribution of subjects in wh-questions in Bianchi, Bocci \& Cruschina (2017) and Bocci \& Cruschina (2018), among others.

\section{Distributed Morphology}

Arregi: A lot of experimental work is carried out in the framework, but this is not my area of expertise. 
Saab: Yes, many issues, which are the heart of the DM program, are being currently investigated under experimental methods and tools. I find particularly promising the way in which some questions related to the epiphenomenal nature of words are being approached by David Embick and colleagues at the University of Pennsylvania.

\section{Minimalism}

Armstrong: While criticisms leveled at Minimalism are sometimes related to the unreliability of traditional elicitation of acceptability judgments as a scientific methodology, experimental techniques form an important part of the research program. For instance, the work of Jon Sprouse and colleagues (general perspective) and Iván Ortega-Santos and colleagues (Romance-specific perspective) demonstrates how experimental methods that complement traditional elicitation have been integrated into research within the framework.

Donati: The minimalist approach has been mostly based on introspective acceptability judgements and abstract speculation. But experimental research has recently started developing based on Minimalist hypotheses in various directions: 1) verifying with controlled experiments the validity of introspective data on issues such as labeling and its relations with movement); 2) exploring the role of structural principles in language parsing; 3) assessing the role of "third factor" principles in driving comprehension and production.

\section{Nanosyntax}

De Clercq: Experimental research has not yet been done within NS, since it is such a young framework. However, several avenues for investigation can be envisaged. One option would be to investigate whether there are delays in processing if a language makes use of a syncretic morpheme for various types of negation, or different cases, as opposed to dedicated markers to express these functions.

Fábregas: Yes, I think like any other theoretical approach. Nanosyntax makes very precise predictions about what should be possible or impossible combinations of exponents, the information encoded in each morpheme and the nature of the underlying structures where those exponents are introduced. Some of the work done here in Troms $\varnothing$ at the PolarLab, again putting variation and language contact in its center, involves precisely these hypotheses.

\section{Does you approach also try to explain the patterns we observe in language acquisition?}

\section{Cartography}

Rizzi: Yes, cartographic representations offer a natural guideline for acquisition research: how are the complex configurations uncovered in cartographic research acquired by the child? Are they mastered piece after piece? With the full range of 
their interface properties? These questions are addressed in the line of research referred to as "growing trees".

Schifano: The application of cartography to language acquisition is again a very fruitful one, thanks to its role as magnifying glass to be applied to patterns of variation, including those attested in L1/L2 learners/speakers, as well as nearnative ones (e.g. Belletti, Bennati \& Sorace 2007), witness extensive investigations by Belletti, Guasti and Sorace, among many others.

\section{Distributed Morphology}

Arregi: Like other generative theories, DM makes strong predictions about patterns in language acquisition, but I'm not very familiar with this type of work.

Saab: Yes, the problem of language acquisition is approached within the general minimalist/P\&P research program. So, in principle, the general questions are exactly the same. An interesting working hypothesis is that some well-known patterns in language acquisition (inflectional, mainly) can be explained with reference to a set of well-defined post-syntactic rules.

\section{Minimalism}

Armstrong: An important desideratum of the generative enterprise since Chomsky's earliest work is to explain patterns in language acquisition. Generative approaches to language acquisition have existed since the inception of the framework, and continue to be a vital aspect of the research program. Admittedly, my knowledge of this discipline is not entirely up to date, but recent overviews of work on the acquisition of Romance languages done within the Minimalist framework can be found in works such Belletti \& Guasti (2015) and GuijarroFuentes et al. (2016).

Donati: The locus of linearization (as a postcyclic phenomenon), the status of movement over merge (a point which has greatly changed in the development of Minimalist theorizing), the source of principles such as the EPP, imposing that all clauses have a subject, etc., are all hypotheses that translate into predictions concerning learnability, complexity and order of acquisition. As such they promote experimental and observational research on children's comprehension or production.

\section{Nanosyntax}

De Clercq: This has not yet been the focus of research in Nanosyntax, but could be pursued. Under a NS account the lexical structure of an irregular verb like English stuck for instance would consist of a pointer, a cross-reference, to the lexical item for stick and to the past tense morphology -ed. It could be argued that the acquisition of irregular verbs comes late due to the fact that cross-references across the lexicon are one of the last things to be established.

Fábregas: The starting hypothesis (which is almost certainly a simplification, but a necessary one at this stage) is that the underlying universal syntactic structure is, if you wish, mentalese, and acquisition of a specific language means learning the specific exponents and the configurations that each one of them spells out. A 
direct consequence is that there are no incomplete grammars: any stage of acquisition corresponds to a possible language; some of the research carried at the AcqVa Aurora Center here and in Trondheim is exploring these questions through different phenomena and language combinations.

\section{What are the main phenomena (in Romance linguistics) addressed within this framework in the last few years?}

\section{Cartography}

Rizzi: Focalization (in the high and low periphery), topicalization (clitic leftdislocation), and their interface properties, questions and relatives, subject positions, subject and object clitic systems, restructuring and causative constructions, the positions of the verb, adverb and adjective distribution, V2 phenomena in the history of Romance.

Schifano: Among the most well-studied phenomena in Romance linguistics, the left periphery (both the high and low one and including phenomena such focalization/topicalization, speech acts and V2) the IP (including phenomena related to subject distribution and verb movement) and interfaces (e.g. syntax with discourse-pragmatics and prosody) have received a great deal of attention in recent times.

\section{Distributed Morphology}

Arregi: As I mentioned above, quite a bit of DM work has been dedicated to Romance pronominal clitics, especially with respect to issues of their form, placement, and constraints on possible clitic clusters. Other topics include agreement, nominalizations and other argument-structure-related phenomena, socalled contractions of different sort (e.g. French $d u$ ), allomorphies of different types (suppletion, stem alternations), etc.

Saab: Well, many, but let us mention some that come to my mind like differential object marking in Spanish and Romanian, mesoclisis in Spanish dialects (and other clitic orderings), the person-case constraint, and the interaction between ellipsis and morphological operations in Romance and other inflectional languages.

\section{Minimalism}

Armstrong: Minimalism, like its generative predecessors, has cast a wide net over a range of empirical phenomena in order to test its hypotheses. These include familiar topics in Romance linguistics such as null subjects, word order and its relation, or lack thereof, to information structure, and clitics. Work within the past decade that I have found enlightening has addressed issues related to argument structure (particularly the nature of datives), the nature of clitics as agreement morphemes or displaced determiners, and the importance of scales in describing the grammatical behavior of adjectives. 
Donati: Movement and labels (on various types of A-bar dependencies such as relatives and interrogatives of various kinds and complement and adjunct clauses); small clauses of different size and type (participial and gerundive clauses, infinitivals and control); participial agreement and auxiliary selection; the nature and behavior of pronominal clitics and pronominal omission.

\section{Nanosyntax}

De Clercq: (French) irregular verbs (Starke 2020), preverbal subjects and interrogatives in Spanish (Fabregas 2018), the Romance nominal complementizer system (Baunaz \& Lander 2018), French negation (De Clercq 2013, 2017, 2020; De Clercq \& Vanden Wyngaerd 2019), gender and number marking on Italian and Spanish nouns (Janku \& Starke 2019), Latin comparative and superlative morphology (De Clercq \& VandenWyngaerd 2017).

Fábregas: I would say that significant contributions have been made in Romance inflectional and derivational morphology (broadly taken, where the focus has been almost always the syntactic and semantic properties of the elements, given that 'morphology' is not taken as a separate component), verbal aspect and mood, case expression -including DOM-, prepositional structures, pronouns and clitics, gender and class markers, subordination, copulative verbs and even word order.

\section{References}

Baunaz, L. \& E. Lander. 2018. Deconstructing categories syncretic with the nominal complementizer. Glossa: a journal of general linguistics, 3(1): 31. DOI: http://doi.org/10.5334/gjgl.349

Belletti, A., Bennati, E. \& A Sorace. 2007. Theoretical and developmental issues in the syntax of subjects: Evidence from near-native Italian. Natural Linguistic Theory (25): 657-689.

Belletti, A. \& M.T. Guasti. 2015. The Acquisition of Italian. Amsterdam: John Benjamins.

Bianchi, V., Bocci, G. \& Silvio Cruschina. 2017. Two types of subject inversion in Italian wh-questions. Revue roumaine de linguistique 62(3): 233-252.

Bocci, G. \& S. Cruschina. 2018. Postverbal subjects and nuclear pitch accent in Italian wh-questions. In Petrosino, R., Cerrone, P. \& H. van der Hulst (eds), From Sounds to Structure. Beyond the Veil of Maya, 467-494. Boston, Berlin: De Gruyter Mouton.

De Clercq, K. 2020. The Morphosyntax of Negative Markers. A Nanosyntactic Account. Mouton de Gruyter.

De Clercq, K. 2013. A Unified Syntax of Negation. PhD dissertation. Ghent: Ghent University.

De Clercq, K. 2017. The Nanosyntax of French Negation. In Cruschina, S., Hartmann, K. \& E. Remberger (eds), Studies on Negation: syntax, semantics, and variation, 49-80. Vienna: Vienna University Press.

De Clercq, K. \& G. Vanden Wyngaerd. 2017. *ABA revisited: Evidence from 
Czech and Latin degree morphology. Glossa: a journal of general linguistics, 2(1), p.69.

DOI: http://doi.org/10.5334/gjgl.371

De Clercq, K. \& G. Vanden Wyngaerd. 2019. On the idiomatic nature of unproductive morphology. In: Linguistics in the Netherlands 36, 99-114. John Benjamins.

Fábregas, Antonio. 2018. Word Order and Nanosyntax: Preverbal Subjects and Interrogatives across Spanish Varieties. In Baunaz, L., De Clercq, K. , Haegeman, L. \& E. Lander (eds): Exploring Nanosyntax, 250-276. Oxford/ New York: Oxford University Press.

Guijarro-Fuentes, P., Juan-Garau M. \& P. Larrañaga (eds). 2016. Acquisition of Romance Languages. Berlin: Mouton de Gruyter.

Janku, L. \& M. Starke. 2019. Class meets gender in Italian and Spanish: A

Nanosyntactic account. Talk presented at Going Romance 2019 (28-29

November 2019). Leiden University Center for Linguistics, The Netherlands.

https://www.universiteitleiden.nl/binaries/content/assets/geesteswetenscha ppen/leiden-university-centre-for-linguistics/goingromance2019_jankustarke.pdf

Starke, M. 2020. Universal Morphology. Invited talk at NELS 51 (6-8

November 2020). Université du Québec à Montréal, Canada. https://uqam.ca.panopto.com/Panopto/Pages/Viewer.aspx?id=c8ad61b31bed-43f6-800a-ac8f0105b1eb 